\title{
Malaria impact on cognitive function of children in a peri-urban community in the Brazilian Amazon
}

\author{
Raquel Tapajós ${ }^{1,2}$, Daniel Castro ${ }^{1,3}$, Gisely Melo 2,4, Seyi Balogun7, Mark James ${ }^{7}$, Rockson Pessoa ${ }^{4}$, \\ Anne Almeida ${ }^{2,4}$, Mônica Costa ${ }^{2}$, Rosemary Pinto', Bernardino Albuquerque', Wuelton Monteiro ${ }^{2,4}$, \\ José Braga ${ }^{3,5}$, Marcus Lacerda ${ }^{2,6,7^{*}}$ and Maria Paula Mourão $0^{2,4}$
}

\begin{abstract}
Background: In Latin America, where Plasmodium vivax malaria is more prevalent, it is known that this species plays an important role in the sustainability of transmission, and can have an impact on morbidity in terms of anaemia, nutritional status, and cognitive development in children.

Methods: The present study aimed to assess the impact of malaria infection on cognition of children in a peri-urban community in the Brazilian Amazon with moderate endemicity by applying Home Inventory and WPPSI-IV. A nonconcurrent cohort study was designed and the cognitive, haematological, and nutritional profiles of the children were assessed. Children with documented malaria history were identified from official reported data.

Results: A total of 219 children aged between 2 and 7 years were enrolled. Although 205 (95\%) children had normal birth weight, 177 (81\%) were malnourished, and 35 (16\%) had anaemia. Among the 100 (46\%) children who experienced at least one episode of malaria, 89 (89\%) children demonstrated low level of cognitive development. The findings showed that Plasmodium vivax malaria was an independent risk factor for low cognitive development.
\end{abstract}

Conclusions: In addition to the known economic impact of malaria in the Amazon region, the study highlights the deleterious effects P. vivax malaria has on the socio-cultural development of the population.

Keywords: Malaria, Plasmodium vivax, Cognition, Children

\section{Background}

Malaria is the second most common cause of infectious disease-related death in the world. It is estimated to affect 210 million people annually and accounts for approximately 450,000 deaths per year [1].

In the Americas, Brazil reports most of the morbidity attributed to malaria, with the disease being responsible for a substantial decrease in the quality of life $[2,3]$. There have been several malaria control efforts in Brazil; nonetheless, children are still greatly affected [4]. Most children living in endemic areas suffer multiple episodes of malaria prior to adolescence. In general, these episodes

\footnotetext{
*Correspondence: marcuslacerda.submissao@gmail.com

2 Fundação de Medicina Tropical Dr. Heitor Vieira Dourado, Manaus, Brazil

Full list of author information is available at the end of the article
}

are acute, not complicated, and children recover after treatment, especially in areas where Plasmodium vivax is frequent $[5,6]$. Studies examining neurological sequelae in children with severe falciparum malaria (mostly cerebral malaria) have shown that there is some impairment in developing cognitive abilities after an acute episode, both in the short-term [7-9] and long-term [10, 11]. Greater clarification on the effects of cumulative or repetitive malaria episodes on cognitive development of children is needed, in particular that caused by $P$. vivax.

Considering that $P$. vivax is more prevalent than Plasmodium falciparum in Brazil [2] and that previous study, also in the Brazilian Amazon, showing that malaria compromises the school performance of children [12], the principal aim the present study was to assess the impact of malaria on cognitive function in children who live in 
the Brasileirinho, a small peri-urban community on the eastern outskirts of Manaus, Brazil.

\section{Methods}

\section{Ethics statement}

The study was approved by the Ethics Review Board of Fundação de Medicina Tropical Dr Heitor Vieira Dourado (FMT-HVD) (approval number 1.066.733/2015). Both the Municipal Secretaria of Education and school directors also approved the study. Parents/guardians signed an informed consent.

\section{Study area and population}

The city of Manaus has a population of 2,020,301 inhabitants, mostly living in urban or suburban areas of the city [13]. In this municipality, intense migratory processes, combined with poor surveillance and entomological detection, results in active malaria transmission in rural and peri-urban areas.

The study site, Brasileirinho, is a community with a reported population of 1574 inhabitants, located in the peri-urban region of eastern Manaus (Fig. 1). At this site, residents are vulnerable to malaria transmission due to standing water and ponds used as community bathing pools. The occurrence of malaria is common in this population since water for sanitation and consumption comes from wells or streams that serve as mosquito breeding sites. This community has access to one malaria clinic specifically conducting malaria diagnosis by microscopy and treatment of cases. Health agents based in this clinic regularly visit homes in order to ensure early detection and treatment of cases.

\section{Study design}

Cross-sectional surveys were conducted in the community, including all inhabitants that were willing to participate in the study. In case of absence of any family members, the team returned to the respective house for a second time. All children living in the area were identified. The community was sensitized and informed about the study and participants were invited to participate.

Inclusion criteria consisted of: age between 2 years and 6 months old (30 months) and 7 years and 7 months old (91 months), and residence in the study area. Exclusion criteria consisted of: presence of reported co-morbidities that are known to affect cognitive development (Autism Spectrum Disorder [ASD], Attention Deficit Disorder Association [ADHD], and other neurological diseases), severe episodes of acute infectious diseases in the last 30 days and/or presence of malaria parasites in peripheral blood during screening. After obtaining consent, a questionnaire was administered to survey participant information about the history of recent illness, sociodemographic data were collected. The history of malaria was confirmed and obtained through of the Information System for Epidemiological Surveillance and Notification of Malaria Cases (SIVEP-Malaria/SVS/MS). This system, the results of the microscopy are typed and stored. All children were positive for $P$. vivax.

A volume of $300 \mu \mathrm{L}$ of blood was collected by finger puncture using Microtainer ${ }^{\circledR}$ tubes containing EDTA and sodium fluoride (Becton-Dickinson, NJ, USA).

\section{Diagnosis of malaria}

Thick blood smears and PCR was performed to confirm negative diagnosis at the time of cognitive evaluation. Thick blood smears were Giemsa-stained according

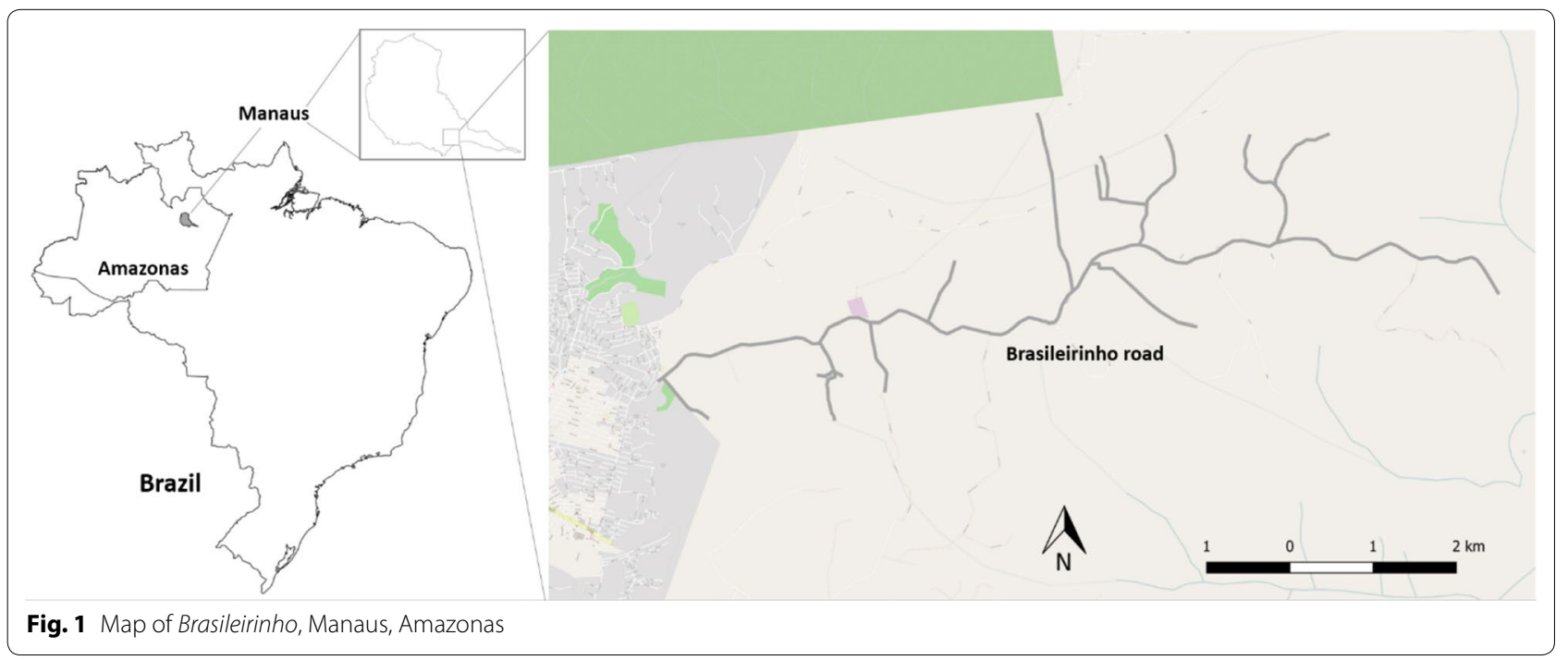


to World Health Organization guidelines [14]. Numbers of asexual blood stage parasites and gametocytes were determined per 200 leukocytes and parasites per $\mu \mathrm{L}$ were calculated using an assumed density of 6000 leukocytes per $\mu \mathrm{L}$ [15]. The reading of the thick blood smears were performed by two trained microscopists (double blind reading). For genomic DNA extraction, a FavorPrep $^{\mathrm{TM}}$ 96-well Genomic DNA Kit (Favorgen, PingTung, Taiwan) was used, according to the manufacturer's instructions. Qmal Taqman PCR was used to detect Plasmodium spp. in DNA samples, as described by Almeida et al. [16].

\section{Cognitive assessment}

An evaluation of cognitive function was conducted to investigate the effect of malaria episodes on cognitive development, taking into account malarial history. Cognitive assessment data were collected at the children's residence or school. Space was provided for the child to carry out the activities proposed by each evaluation instrument. Data collection was carried out by psychologists, trained in the use of cognitive assessment tools. This assessment allowed the development of more complex and conclusive causal models in the role of infection on the child's cognitive functions.

Proper guidance by the research team on how to seek specialized care was given to caregivers of children who were diagnosed with cognitive impairment or severe malnutrition.

\section{Instruments used WPPSI-IV}

Wechsler Preschool and Primary Scale of Intelligence-IV (WPPSI-IV) [17] allows evaluation of children beginning at age 2 years and 6 months until the limit of 7 years and 7 months of age. The test is known to have good correlation with other tests that evaluate cognitive development, such as Wechsler Intelligence Scale for Children (WISC). It consists of a battery of tasks to be performed by the child, grouped into two large blocks, executive and verbal, that enable the evaluation of different areas of cognition, summarized in the end by an overall score. A total of four cognitive sub-tests were completed with children ages 2 years, 6 months to 3 years, 11 months (verbal comprehension, working memory, visual spatial, and full scale); and six tests on children ages 4 years, to 7 years, 7 months (fluid reasoning and processing speed, in addition to the previously stated tests). The full-scale composite score is derived from the four or six subtests, and summarizes the ability across a diverse set of cognitive functions, such as verbal comprehension, working memory and processing speed. This score is considered the most representative indicator of global intellectual functioning. The full-scale scores for the analysis of cognition was used.

Although the WPPSI-IV scale has not yet been validated for the Brazilian children, previous research [18] of this, as well as the WISC scale (Weschler Scale for Children) were used in the Brazilian population and showed good reliability and resulting similar to that found in this study.

\section{Home inventory}

The Resource Inventory Home Environment (RAF) evaluates the quality of the home environment in the first years of life [19]. HOME Inventory assesses resources of the family environment that could contribute to learning in three domains: resources that promote proximal processes; activities that signal stability in family life; and parenting practices that promote family-school connection. This version consists of ten questions that correspond to resource areas previously identified.

The resource area that promotes proximal processes, stimulates participation in developmental experiences such as tours and travel; opportunities to interact with parents; availability of toys and materials that present challenge to thinking; availability of books, newspapers and magazines; proper use of free time; and access to scheduled learning activities. Routines and regular family meetings, and child cooperation housekeeping chores, are included in the activities domain and signal stability in family life. Finally, parental practices that promote bonding domain, e.g., family-school involvement including direct indicators of parents in school life, and participation in teacher-parent meetings for follow-up of academic performance (grades earned). The HOME Inventory was carried out to see if other factors within the home may have a confounding effect on cognition.

\section{Nutritional assessment}

Weight and height were measured by internationally accepted methods [20]. Weight was measured by use of a digital scale, and height was assessed by a single observer with the use of a tape measure. Body Mass Index (BMI) was calculated using the program EPI-INFO version 7.0. BMI Z-score $<-2$ was defined as malnutrition; scores between -2 and $Z<-1$ as underweight (risk zone); $Z$ score between -1 and 2 , normal weight; and $Z$ score $>2$ as obesity.

\section{Haemoglobin}

Haemoglobin concentration was measured in venous blood obtained from digital puncture, using a portable HemoCue ${ }^{\circledR}$ photometer (Anglholm, Sweden). 


\section{Stool examination}

Stool samples from children included in the study were collected. Analysis of the faecal material was performed using Kato-Katz method, which allows the identification and quantification (number/g of faeces) of a certain helminth infection (Ascaris lumbricoides, hookworm, Schistosoma mansoni, Trichuris trichiura, Taenia sp, Enterobius vermicularis and Strongyloides stercoralis).

\section{Analytical procedures}

A model of hierarchical analysis was developed to determine the influence of the home environment, socioeconomic characteristics of caregivers, child nutritional status, and the effect of intestinal helminthiasis on cognitive development measures. The variables were arranged in hierarchical blocks according to their nature and impact on the outcome studied.

Socio-economic status was measured, based on the following variables: (1) household income (families with income equal to or less than 1 minimum wage); (2) running water (families that have water piped into their homes); (3) sewer (families that have network sewage disposal); and (4) home density (number of residents in the house).

The child's health status was assessed, based on variables relating to: (1) malnutrition (measured by height for age and weight by age, according to the standard adopted by the World Health Organization); (2) anemia (in which children with a haemoglobin concentration $<11.0 \mathrm{~g} / \mathrm{dL}$ are considered anaemic); (3) intestinal parasites (occurrence of intestinal parasitosis and species found in faecal specimens); (4) low birth weight (based on health registry, considering neonates weighing less than $2500 \mathrm{~g}$ at birth); (5) premature birth (measured by records of gestational age at birth, considering those born before the 37th week of gestation); (6) breastfeeding practices (exclusive breastfeeding for at least the first 6 months of life); (7) vaccination (measured by the child's health records); (8) infectious diseases (occurrence of infectious diseases in the last 30 days prior to the cognitive assessment); and (9) chronic diseases (presence of chronic disease in the child's medical history).

Organization of the family unit was evaluated by the following variables: (1) adolescent mother (mothers under 18 years of age); (2) mother's educational level (at least a year of study as reported by mother); (3) family stimulus (measured by the HOME Inventory information, considering four categories according to the final score inventory: more stimulated, regularly stimulated, little stimulated, almost no stimulus); (4) disorders during pregnancy (measured by information relating to the diagnosis of infectious diseases during pregnancy).
Information related to the presence of malaria was evaluated using the following variables: (1) malaria history (at least one prior malaria episode in the child); (2) number of episodes (number of malaria episodes); (3) age/malaria (age at the last episode of malaria); (4) exposure to malaria (measured according to four categories: no exposure-never had malaria; mild-had one episode at 5 years or older; moderate-had one episode prior to 2 years of age, or more than one episode after 2 years of age; severe-had at least two episodes prior to 2 years of age); (5) severe malaria and hospitalization (if there was hospitalization during the malaria episode); (6) malaria and breast feeding (occurrence of malaria episode during the 6-month breast feeding period); and (7) malaria and pregnancy (occurrence of malaria attacks during pregnancy that led to the child being studied).

\section{Data analysis}

Descriptive statistical analyses were performed to characterize the socio-demographic characteristics of children in relation to the level of cognitive development. Different scores of cognitive impairment were used in children to improve understanding of the effect of this disease state on cognitive development.

Associations were tested between cognitive performance and each of the risk factors by logistic regression analysis, assuming a 5\% significance level. To better understand the multiplicity of cognitive development, the variables were organized by blocks, according to its nature and impact on the outcome.

Associations with statistical significance in univariate analysis were tested, using a model of hierarchical logistic regression. A step-wise procedure for selecting variables in the multivariate analysis was used. The final model was developed using only the variables that presented an association with the outcome at a 5\% significance level. All statistical tests were performed with Stata (Stata Corp, College Station, Texas, USA).

\section{Results}

Initially, 263 children were available in the area study and were screened for the presence of malaria parasites. Ten children who were PCR-positive for Plasmodium vivax and 34 children failed to perform the cognition test within the time provided, in accordance with WPPSI-IV recommendations were excluded. A total of 219 children, ages 2-7 years old, were evaluated in a non-concurrent cohort study allowing for the observation of malaria exposure status and its effect on cognitive function.

A total of 219 students aged between 2 and 7 years $(\bar{x}=4$ years of age) were enrolled; $114(52 \%)$ male, and 105 (48\%) female. Of this total, 97 (44\%) were students. Regarding socioeconomic status, 20 (9\%) families 
received less than 1 minimum wage; most residences did not have piped water (60\%) or sewage system (98\%), and the houses presented with high household crowding (26\%). In the group of maternal and family conditions, 119 (50\%) children had little or almost no family stimulus, and 198 (91\%) of the mothers lacked education. Although 205 (95\%) children had normal birth weight, 177 (81\%) were malnourished, and 35 (16\%) had anaemia. Among the 100 (46\%) children who experienced at least one episode of malaria, 89 (89\%) children demonstrated low level of cognitive development (Table 1).

Children who had had at least one episode of malaria had lower mean scores for each of the dimensions assessed in WPPSI-IV compared to those who had never had malaria (Table 2). It is noteworthy that the scores of the dimensions of the WPPSI scale obtained in this study showed an asymmetric distribution with a high proportion of children with low scores. For the purposes of analysis, it was determined that children with a final score of 59.65 and lower (25\% percentile) were considered with low cognitive development.

Bivariate analysis using logistic regression models showed that children with anemia $(\mathrm{OR}=2.24$; IC 95\% 0.64-7.78), and who had had one episode or more of malaria $(\mathrm{OR}=2$; IC 95\% 0.95-4.41) were more likely to have low cognitive development. None of the variables related to maternal and family conditions were associated with the outcome at the $5 \%$ significance level in the bivariate logistic regression model. With multiple regression analysis, associations between low cognitive development and children with anemia $(\mathrm{OR}=2.9$; IC 95\% 0.8110.22), and occurrence of an episode or more of malaria $(\mathrm{OR}=2.2$; IC 95\% 1-4.85) remained statistically significant (Table 3). These factors showed a greater magnitude in the measure of association.

\section{Discussion}

The findings showed that malaria infection is associated with low cognitive development in children. A survey of 219 children living in a peri-urban area of Manaus showed a high proportion of children with low cognitive development living in poor sanitation conditions, low maternal and family stimulation for learning, with high exposure to malaria. When controlling for potential confounding variables, malaria infections remained as a predictor for low cognitive development in the study population (Table 3).

Studies indicate that malnourished children with high levels of exposure to parasitic diseases [21-23], with low socioeconomic status [24-26], born to young mothers with no schooling $[27,28]$, are prone to result in poor performance in cognitive tests and language. In a study carried out in Ethiopia, certificated that compared to non-anemic children, anemic children had lower score for the verbal reasoning test [29]. In other study conducted in Peru, found an association between having been infected with ascaris or any STH between one and two years of age and lower cognitive and verbal abilities later in childhood [30].

Favorable environmental conditions, such as adequate stimuli and appropriate family conditions, seem to exert a positive influence on child development [31]. However in this study, no association was found between the cognitive function of the child and the condition of maternal or family stimulation. Possibly, this relationship was not observed due to the low variability of the family stimulus conditions (only $25 \%$ are more stimulated) and the mother's educational level ( $90 \%$ of the mothers lack formal education) in the study population.

The children studied were highly infected with intestinal parasites and were malnourished; 35 (16\%) children had anaemia during the period of data collection. The latter condition showed association with low cognitive development (OR 2.245; CI 95\% 0.647-7.785). These findings corroborate studies conducted in Indonesia and sub-Saharan African countries that showed the relationship between anaemia (59\%), malnutrition (35\%) and cognitive development in preschool children [32,33].

The impact of malaria on childhood cognitive performance has been demonstrated in studies that investigated P. falciparum infection [34-36], in which the occurrence of cerebral malaria is more frequent and may result in severe neurological sequelae [37]. Despite the evidence that $P$. vivax malaria can also be associated with neurological impairment [38] and the occurrence of cognitive dysfunction even in uncomplicated malaria [5], little is known about the impact of this infection on cognitive function.

Like other studies that have evaluated cognitive ability in children in Brazil, we found a high proportion (84\%) of children with low cognitive development [12, 39]. VitorSilva et al., studying children from a rural area of the state of Amazonas where $P$. vivax infection is predominant, showed that the occurrence of at least one episode of malaria throughout the school year was associated with poor school performance (Portuguese or Mathematics subjects) [12].

Brasil et al. found a significant impairment of verbal and full-scale quotients as well as a significant low index of verbal comprehension [40]. The findings corroborate these results, showing that malaria infection is related to the low cognitive development of children in a highly endemic area for $P$. vivax malaria, independent of the socioeconomic status, the family and maternal stimulus, and the child's health status $[39,41]$. 
Table 1 Characteristics of children studied according to the level of cognitive development

\begin{tabular}{|c|c|c|c|c|c|c|}
\hline \multirow[t]{2}{*}{ Characteristic } & \multicolumn{2}{|c|}{ No low cognitive development } & \multicolumn{2}{|c|}{ Low cognitive development } & \multicolumn{2}{|c|}{ Total } \\
\hline & $\mathbf{N}$ & $\%$ & $\mathbf{N}$ & $\%$ & $\mathrm{~N}$ & $\%$ \\
\hline \multicolumn{7}{|l|}{ Demographic } \\
\hline \multicolumn{7}{|l|}{ Sex } \\
\hline Male & 16 & 14.0 & 98 & 86.0 & 114 & 100.0 \\
\hline Female & 19 & 18.1 & 86 & 81.9 & 105 & 100.0 \\
\hline Total & 35 & & 184 & & 219 & \\
\hline \multicolumn{7}{|l|}{ Age } \\
\hline $2.6-3.11$ & 15 & 21.1 & 56 & 78.9 & 71 & 100.0 \\
\hline $4-7.7$ & 20 & 13.5 & 128 & 86.5 & 148 & 100.0 \\
\hline Total & 35 & & 184 & & 219 & \\
\hline \multicolumn{7}{|l|}{ Education } \\
\hline Not study & 24 & 19.7 & 98 & 80.3 & 122 & 100.0 \\
\hline Study & 11 & 11.3 & 86 & 88.7 & 97 & 100.0 \\
\hline Total & 35 & & 184 & & 219 & \\
\hline \multicolumn{7}{|l|}{ Socio-economic } \\
\hline \multicolumn{7}{|l|}{ Brick-built house } \\
\hline No & 23 & 16.4 & 117 & 83.6 & 140 & 100.0 \\
\hline Yes & 12 & 15.2 & 67 & 84.8 & 79 & 100.0 \\
\hline Total & 35 & & 184 & & 219 & \\
\hline \multicolumn{7}{|l|}{ Family income } \\
\hline$\leq 1$ min. wage & 3 & 15.0 & 17 & 85.0 & 20 & 100.0 \\
\hline$>1$ min. wage & 32 & 16.1 & 167 & 83.9 & 199 & 100.0 \\
\hline Total & 35 & & 184 & & 219 & \\
\hline \multicolumn{7}{|l|}{ Piped water } \\
\hline No & 28 & 21.2 & 104 & 78.8 & 132 & 100.0 \\
\hline Yes & 7 & 8.0 & 80 & 92.0 & 87 & 100.0 \\
\hline Total & 35 & & 184 & & 219 & \\
\hline \multicolumn{7}{|l|}{ Sewage system } \\
\hline No & 34 & 15.8 & 181 & 84.2 & 215 & 100.0 \\
\hline Yes & 1 & 25.0 & 3 & 75.0 & 4 & 100.0 \\
\hline Total & 35 & & 184 & & 219 & \\
\hline \multicolumn{7}{|l|}{ Housing conditions } \\
\hline Precarious & 7 & 15.2 & 39 & 84.8 & 46 & 100.0 \\
\hline Reasonable & 21 & 22.1 & 74 & 77.9 & 95 & 100.0 \\
\hline Better conditions & 7 & 9.0 & 71 & 91.0 & 78 & \\
\hline Total & 35 & & 184 & & 219 & \\
\hline \multicolumn{7}{|l|}{$>2$ residents/room } \\
\hline No & 27 & 16.7 & 135 & 83.3 & 162 & 100.0 \\
\hline Yes & 8 & 14.0 & 49 & 86.0 & 57 & 100.0 \\
\hline Total & 35 & & 184 & & 219 & \\
\hline \multicolumn{7}{|c|}{ Maternal and family conditions } \\
\hline \multicolumn{7}{|l|}{ Adolescent mother } \\
\hline No & 34 & 15.7 & 183 & 84.3 & 217 & 100.0 \\
\hline Yes & 1 & 50.0 & 1 & 50.0 & 2 & 100.0 \\
\hline Total & 35 & & 184 & & 219 & \\
\hline \multicolumn{7}{|l|}{ Mother's education } \\
\hline Not study & 31 & 15.7 & 167 & 84.3 & 198 & 100.0 \\
\hline Study & 4 & 19.0 & 17 & 81.0 & 21 & 100.0 \\
\hline Total & 35 & & 184 & & 219 & \\
\hline
\end{tabular}


Table 1 (continued)

\begin{tabular}{|c|c|c|c|c|c|c|}
\hline \multirow[t]{2}{*}{ Characteristic } & \multicolumn{2}{|c|}{ No low cognitive development } & \multicolumn{2}{|c|}{ Low cognitive development } & \multicolumn{2}{|c|}{ Total } \\
\hline & $\mathbf{N}$ & $\%$ & $\mathbf{N}$ & $\%$ & $\mathrm{~N}$ & $\%$ \\
\hline \multicolumn{7}{|c|}{ Disorders during pregnancy } \\
\hline No & 33 & 16.9 & 162 & 83.1 & 195 & 100.0 \\
\hline Yes & 2 & 8.3 & 22 & 91.7 & 24 & 100.0 \\
\hline Total & 35 & & 184 & & 219 & \\
\hline \multicolumn{7}{|l|}{ Level of family stimulus } \\
\hline More stimulated & 5 & 9.1 & 50 & 90.9 & 55 & 100.0 \\
\hline Regularly stimulated & 9 & 16.4 & 46 & 83.6 & 55 & 100.0 \\
\hline Little stimulated & 12 & 21.1 & 45 & 78.9 & 57 & 100.0 \\
\hline Almost no stimulus & 9 & 17.3 & 43 & 82.7 & 52 & 100.0 \\
\hline Total & 35 & & 184 & & 219 & \\
\hline \multicolumn{7}{|l|}{ Child health } \\
\hline \multicolumn{7}{|l|}{ Malnutrition } \\
\hline No & 8 & 19.0 & 34 & 81.0 & 42 & 100.0 \\
\hline Yes & 27 & 15.3 & 150 & 84.7 & 177 & 100.0 \\
\hline Total & 35 & & 184 & & 219 & \\
\hline \multicolumn{7}{|l|}{ Anemia } \\
\hline No & 32 & 17.4 & 152 & 82.6 & 184 & 100.0 \\
\hline Yes & 3 & 8.6 & 32 & 91.4 & 35 & 100.0 \\
\hline Total & 35 & & 184 & & 219 & \\
\hline \multicolumn{7}{|l|}{ Intestinal parasites } \\
\hline No & 6 & 16.7 & 30 & 83.3 & 36 & 100.0 \\
\hline Yes & 29 & 15.8 & 154 & 84.2 & 183 & 100.0 \\
\hline Total & 35 & & 184 & & 219 & \\
\hline \multicolumn{7}{|l|}{ Low birth weight } \\
\hline No & 33 & 16.1 & 172 & 83.9 & 205 & 100.0 \\
\hline Yes & 2 & 16.7 & 10 & 83.3 & 12 & 100.0 \\
\hline Total & 35 & & 182 & & 217 & \\
\hline \multicolumn{7}{|l|}{ Premature birth } \\
\hline No & 32 & 15.5 & 174 & 84.5 & 206 & 100.0 \\
\hline Yes & 3 & 23.1 & 10 & 76.9 & 13 & 100.0 \\
\hline Total & 35 & & 184 & & 219 & \\
\hline \multicolumn{7}{|c|}{ Breast feeding until the sixth month } \\
\hline No & 12 & 14.0 & 74 & 86.0 & 86 & 100.0 \\
\hline Yes & 12 & 16.4 & 61 & 83.6 & 73 & 100.0 \\
\hline Total & 24 & & 135 & & 159 & \\
\hline \multicolumn{7}{|l|}{ Vaccinated } \\
\hline No & 1 & 4.5 & 21 & 95.5 & 22 & 100.0 \\
\hline Yes & 34 & 17.4 & 161 & 82.6 & 195 & 100.0 \\
\hline Total & 35 & & 182 & & 217 & \\
\hline \multicolumn{7}{|c|}{ Infectious disease in the last 30 days } \\
\hline No & 34 & 15.8 & 181 & 84.2 & 215 & 100.0 \\
\hline Yes & 1 & 25.0 & 3 & 75.0 & 4 & 100.0 \\
\hline Total & 35 & & 184 & & 219 & \\
\hline \multicolumn{7}{|l|}{ Chronic diseases } \\
\hline No & 34 & 15.8 & 181 & 84.2 & 215 & 100.0 \\
\hline Yes & 1 & 25.0 & 3 & 75.0 & 4 & 100.0 \\
\hline Total & 35 & & 184 & & 219 & \\
\hline
\end{tabular}


Table 1 (continued)

\begin{tabular}{|c|c|c|c|c|c|c|}
\hline \multirow[t]{2}{*}{ Characteristic } & \multicolumn{2}{|c|}{ No low cognitive development } & \multicolumn{2}{|c|}{ Low cognitive development } & \multicolumn{2}{|c|}{ Total } \\
\hline & $\mathbf{N}$ & $\%$ & $\mathbf{N}$ & $\%$ & $\mathbf{N}$ & $\%$ \\
\hline \multicolumn{7}{|l|}{ Exposure to malaria } \\
\hline \multicolumn{7}{|l|}{ Occurrence of malaria } \\
\hline No malaria history & 24 & 20.2 & 95 & 79.8 & 119 & 100.0 \\
\hline Had an episode/more & 11 & 11.0 & 89 & 89.0 & 100 & 100.0 \\
\hline Total & 35 & & 184 & & 219 & \\
\hline \multicolumn{7}{|c|}{ Number of malaria episodes } \\
\hline 1 & 7 & 10.8 & 58 & 89.2 & 65 & 100.0 \\
\hline 2 & 1 & 8.3 & 11 & 91.7 & 12 & 100.0 \\
\hline 3 & 2 & 14.3 & 12 & 85.7 & 14 & 100.0 \\
\hline 4 & 1 & 11.1 & 8 & 88.9 & 9 & 100.0 \\
\hline Total & 11 & & 89 & & 100 & \\
\hline \multicolumn{7}{|l|}{ Exposure to malaria } \\
\hline No exposure & 24 & 20.2 & 95 & 79.8 & 119 & 100.0 \\
\hline Mild & 1 & 9.1 & 10 & 90.9 & 11 & 100.0 \\
\hline Moderate & 8 & 10.8 & 66 & 89.2 & 74 & 100.0 \\
\hline Severe & 2 & 13.3 & 13 & 86.7 & 15 & \\
\hline Total & 35 & & 184 & & 219 & \\
\hline \multicolumn{7}{|c|}{ Malaria-related hospitalization } \\
\hline No & 9 & 9.8 & 83 & 90.2 & 92 & 100.0 \\
\hline Yes & 1 & 25.0 & 3 & 75.0 & 4 & 100.0 \\
\hline Total & 10 & & 86 & & 96 & \\
\hline \multicolumn{7}{|l|}{ Malaria during pregnancy } \\
\hline No & 30 & 15.5 & 164 & 84.5 & 194 & 100.0 \\
\hline Yes & 5 & 20.0 & 20 & 80.0 & 25 & 100.0 \\
\hline Total & 35 & & 184 & & 219 & \\
\hline \multicolumn{7}{|c|}{ Malaria attacks during pregnancy } \\
\hline No & 9 & 9.8 & 83 & 90.2 & 92 & 100.0 \\
\hline Yes & 1 & 25.0 & 3 & 75.0 & 4 & 100.0 \\
\hline Total & 10 & & 86 & & 96 & \\
\hline
\end{tabular}

Table 2 Cognitive assessment dimensions of exposure to malaria

\begin{tabular}{|c|c|c|c|c|c|c|}
\hline Variable & Groups of children (n) & Average score & SD of score & $\begin{array}{l}\text { Minimum } \\
\text { score }\end{array}$ & $\begin{array}{l}\text { Maximum } \\
\text { score }\end{array}$ & $P$ value \\
\hline \multirow[t]{2}{*}{ ICV_Verbal comprehension index } & Without malaria $(n=119)$ & 65.3 & 17.7 & 45 & 138 & 0.004 \\
\hline & With malaria $(n=100)$ & 59.5 & 13.5 & 45 & 111 & \\
\hline \multirow[t]{2}{*}{ IOP_-Perceptive organization index } & Without malaria $(n=119)$ & 69.0 & 18.0 & 45 & 129 & 0.0005 \\
\hline & With malaria $(n=100)$ & 61.6 & 14.4 & 42 & 109 & \\
\hline \multirow[t]{2}{*}{ IMT_Working memory índex } & Without malaria $(n=119)$ & 69.8 & 17.7 & 45 & 113 & 0.0055 \\
\hline & With malaria $(n=100)$ & 63.7 & 17.4 & 45 & 126 & \\
\hline \multirow[t]{2}{*}{ CIT_Total intelligence quotient } & Without malaria $(n=119)$ & 66.4 & 21.4 & 40 & 155 & 0.0087 \\
\hline & With malaria $(n=100)$ & 60.3 & 14.9 & 40 & 117 & \\
\hline \multirow[t]{2}{*}{ IVP_-Processing speed index } & Without malaria $(n=119)$ & 69.7 & 17.2 & 45 & 115 & 0.0544 \\
\hline & With malaria $(n=100)$ & 65.4 & 15.7 & 43 & 109 & \\
\hline \multirow[t]{2}{*}{ IRA_Abstract reasoning index } & Without malaria $(n=119)$ & 67.4 & 15.1 & 43 & 100 & 0.0135 \\
\hline & With malaria & 62.0 & 14.5 & 43 & 114 & \\
\hline
\end{tabular}


Table 3 Factors associated with low level of cognitive development using univariate and multivariate hierarchical level analysis

\begin{tabular}{|c|c|c|c|c|c|}
\hline Factors & $\%$ & OR & $\mathrm{Cl} 95 \%$ & OR adjusted & $\mathrm{Cl} 95 \%$ \\
\hline \multicolumn{6}{|l|}{ Socio-economic } \\
\hline \multicolumn{6}{|l|}{ Brick-built house } \\
\hline No & 63.9 & 1 & & & \\
\hline Yes & 36.1 & 1097 & $0.513-2.346$ & & \\
\hline \multicolumn{6}{|l|}{ Family income } \\
\hline$\leq 1$ min. wage & 9.1 & 1 & & & \\
\hline$>1$ min. wage & 90.9 & 0.92 & $0.254-3.326$ & & \\
\hline \multicolumn{6}{|l|}{ Sewage system } \\
\hline No & 98.2 & 1 & & & \\
\hline Yes & 1.8 & 0.563 & $0.569-5.579$ & & \\
\hline \multicolumn{6}{|l|}{ Housing conditions } \\
\hline Precarious & 21 & 1 & & & \\
\hline Reasonable & 43.4 & 0.632 & $0.247-1.617$ & & \\
\hline Better conditions & 35.6 & 1820 & $0.595-5.569$ & & \\
\hline \multicolumn{6}{|l|}{$>2$ residents/room } \\
\hline No & 73.9 & 1 & & & \\
\hline Yes & 26.1 & 1.225 & $0.521-2.877$ & & \\
\hline \multicolumn{6}{|c|}{ Maternal and family conditions } \\
\hline \multicolumn{6}{|l|}{ Adolescent mother } \\
\hline No & 99.1 & 1 & & & \\
\hline Yes & 0.1 & 0 & $0.011-3.042$ & & \\
\hline \multicolumn{6}{|l|}{ Mother's education } \\
\hline Not study & 90.4 & 1 & & & \\
\hline Study & 9.6 & 1 & $0.248-2.503$ & & \\
\hline \multicolumn{6}{|c|}{ Disorders during pregnancy } \\
\hline No & 89.1 & 1 & & & \\
\hline Yes & 10.9 & 2240 & $0.502-9.993$ & & \\
\hline \multicolumn{6}{|l|}{ Level of family stimulus } \\
\hline More stimulated & 25.1 & 1 & & & \\
\hline Regularly stimulated & 25.1 & 0.511 & $0.159-1.637$ & & \\
\hline Little stimulated & 26.1 & 0.375 & $0.122-1.147$ & & \\
\hline Almost no stimulus & 23.7 & 0.477 & $0.148-1.534$ & & \\
\hline \multicolumn{6}{|l|}{ Child health } \\
\hline \multicolumn{6}{|l|}{ Malnutrition } \\
\hline No & 19.2 & 1 & & & \\
\hline Yes & 80.8 & 1307 & $0.543-3.127$ & & \\
\hline \multicolumn{6}{|l|}{ Anemia } \\
\hline No & 84.1 & 1 & & 1 & \\
\hline Yes & 15.9 & 2245 & $0.647-7.785$ & 2.877 & $0.810-10.221$ \\
\hline \multicolumn{6}{|l|}{ Intestinal parasites } \\
\hline No & 16.4 & 1 & & & \\
\hline Yes & 83.6 & 1.062 & $0.405-2.779$ & & \\
\hline \multicolumn{6}{|l|}{ Premature birth } \\
\hline No & 94.1 & 1 & & & \\
\hline Yes & 5.9 & 0.613 & $0.159-2.350$ & & \\
\hline \multicolumn{6}{|l|}{ Low birth weight } \\
\hline No & 94.5 & 1 & & & \\
\hline Yes & 5.5 & 0.959 & $0.200-4.579$ & & \\
\hline
\end{tabular}


Table 3 (continued)

\begin{tabular}{|c|c|c|c|c|c|}
\hline Factors & $\%$ & OR & $\mathrm{Cl} 95 \%$ & OR adjusted & $\mathrm{Cl} 95 \%$ \\
\hline \multicolumn{6}{|c|}{ Breastfeeding until the sixth month } \\
\hline No & 54.1 & 1 & & & \\
\hline Yes & 45.9 & 0.824 & $0.345-1.965$ & & \\
\hline \multicolumn{6}{|l|}{ Vaccinated } \\
\hline No & 10.1 & 1 & & & \\
\hline Yes & 89.9 & 0.225 & $0.029-1.734$ & & \\
\hline \multicolumn{6}{|c|}{ Infectious disease in the last 30 days } \\
\hline No & 98.2 & 1 & & & \\
\hline Yes & 1.8 & 0.563 & $0.569-5.579$ & & \\
\hline \multicolumn{6}{|l|}{ Chronic diseases } \\
\hline No & 98.2 & 1 & & & \\
\hline Yes & 1.8 & 0.563 & $0.569-5.579$ & & \\
\hline \multicolumn{6}{|l|}{ Exposure to malaria } \\
\hline \multicolumn{6}{|l|}{ Occurrence of malaria } \\
\hline No malaria history & 54.3 & 1 & & 1 & \\
\hline Had an episode/more & 45.7 & 2044 & $0.946-4.414$ & 2.205 & $1.002-4.853$ \\
\hline \multicolumn{6}{|c|}{ Number of malaria episodes } \\
\hline 1 & 65 & 1 & & & \\
\hline 2 & 12 & 1.327 & $0.148-11.888$ & & \\
\hline 3 & 14 & 0.724 & $0.133-3.924$ & & \\
\hline 4 & 9.0 & 1 & $0.104-8.906$ & & \\
\hline \multicolumn{6}{|l|}{ Exposure to Malaria } \\
\hline No exposure & 54.3 & 1 & & & \\
\hline Mild & 5.0 & 2.526 & $0.308-20.709$ & & \\
\hline Moderate & 33.8 & 2.084 & $0.882-4.923$ & & \\
\hline Severe & 6.9 & 1.642 & $0.346-6.194$ & & \\
\hline \multicolumn{6}{|c|}{ Malaria-related hospitalization } \\
\hline No & 95.8 & 1 & & & \\
\hline Yes & 4.1 & 0.325 & $0.030-3.463$ & & \\
\hline \multicolumn{6}{|l|}{ Malaria during pregnancy } \\
\hline No & 88.6 & 1 & & & \\
\hline Yes & 11.4 & 0.731 & $0.254-2.100$ & & \\
\hline \multicolumn{6}{|c|}{ Malaria attacks during pregnancy } \\
\hline No & 94.1 & 1 & & & \\
\hline Yes & 5.9 & 0.4 & $0.116-1.382$ & & \\
\hline
\end{tabular}

$\mathrm{OR}$, odds ratio; $\mathrm{Cl}$, confidence interval

Considering that, in the present study, the predominantly affected age group with low cognitive performance was 4-7.7 years old, it is assumed that the impact of malaria on cognitive function is not prolonged. The majority presented with moderate exposure, with episodes up to 2 years or more of age. This result corroborates with that recently described in the literature in which $73 \%$ of children in a retrospective cohort study had experienced 1-2 episodes of malaria; $80 \%$ of these infections occurred in the previous $2-3$ years [35].
Most children in this study only had one documented case of malaria. This is clinically significant in that if only one case of malaria can account for this significant decrease in cognition, it is then extremely important to take the necessary precautionary measures against malarial infection in children. This study argues for further research on the cognitive effects of $P$. vivax malaria infections in children. Further implications for research may lead to applying this same tool to children in other regions of Brazil that are also endemic for $P$. vivax malaria. 


\section{Limitations of the study}

The major limitation is that the study is underpowered for multivariate analyses, given the small numbers of children without a history of malaria and the small number of children reportedly without cognitive impairment.

Comparison of this study with others is limited by the fact that this is the only study of its kind to adapt an English cognitive tool for research with Brazilian children and culture. There is no standardized tool which can be utilized globally due to cultural differences [33].

Additionally, children living in Brasilerinho generally seem to have low cognitive development as full-scale scores were on average extremely low independent of malaria infection status. This may be due to the fact that many of these children are not in school, as it is believed that it is more important to work, or learn the family trade, than to obtain a formal education.

These findings showed that the occurrence of malaria had a negative effect on cognitive performance in the study population. However, it emphasizes the need for studies with longer follow-up periods. In endemic areas for malaria in Latin America, where P. vivax predominates, it is important to include parameters on transmission dynamics of transmission and pathogenesis to predict the real impact of $P$. vivax malaria on cognitive function.

The finding of several conditions that can affect cognitive development reinforces the need to implement practices to assess a child's cognitive performance within an integrated vision of child health policies. Due to brain plasticity, the child responds better to therapies and stimuli from the environment, especially in early childhood.

\section{Conclusion}

This study has shown that at least one episode of malaria in children results in a decrease in cognition in a $P$. vivaxendemic area in the Brazilian Amazon. In addition to known economic impacts of malaria in the Amazon region, this study highlights the deleterious effects of this endemic on the socio-cultural development of the population.

\begin{abstract}
Abbreviations
WPPSI-IV: Wechsler Preschool and Primary Scale of Intelligence-IV; qPCR: polymerase chain reaction quantitative; ASD: Autism Spectrum Disorder; ADHD: Attention Deficit Disorder Association; PCR: polymerase chain reaction; DNA: deoxyribonucleic acid; WISC: Wechsler Intelligence Scale for Children; RAF: Resource Inventory Home Environment; BMI: Body Mass Index; STH: soiltransmitted helminthiasis.
\end{abstract}

\section{Acknowledgements}

We thank all of the subjects who participated in the study, as well as the research teams at the Tropical Medicine Foundation and the Amazon Health Surveillance Foundation in Manaus, Brazil.

\section{Authors' contributions}

RT, DC, AA, MC collected data in the field; RP, BA supported field work; SB, GM, MJ, RP, WM, JB performed data analysis; ML, MPM conceived the study and drafted the manuscript. All authors revised the final manuscript. All authors read and approved final manuscript.

\section{Funding}

National Council for Scientific and Technological Development (CNPq) (Cogmal Study, Process Number 486989/2012-7). WM and ML are CNPq fellows.

\section{Availability of data and materials}

The datasets during and/or analyzed during the current study available from the corresponding author on reasonable request.

\section{Ethics approval and consent to participate}

The study was approved by the Ethics Review Board of Fundação de Medicina Tropical Dr Heitor Vieira Dourado (FMT-HVD) (Approval Number 1.066.733/2015). Both the Municipal Secretaria of Education and school directors also approved the study. Parents/guardians signed an informed consent.

\section{Consent for publication}

Not applicable.

\section{Competing interests}

The authors declare that they have no competing interests.

\section{Author details}

${ }^{1}$ Fundação de Vigilância em Saúde do Amazonas, Manaus, Brazil. ${ }^{2}$ Fundação de Medicina Tropical Dr. Heitor Vieira Dourado, Manaus, Brazil. ${ }^{3}$ Escola Nacional de Saúde Pública Sérgio Arouca, FIOCRUZ, Rio de Janeiro, Brazil. ${ }^{4}$ Escola Superior de Ciências da Saúde, Universidade do Estado do Amazonas, Manaus, Brazil. ${ }^{5}$ Instituto de Medicina Social, Universidade do Estado do Rio de Janeiro, Rio de Janeiro, Brazil. ${ }^{6}$ Instituto Leônidas e Maria Deane, FIOCRUZ, Manaus, Brazil. ${ }^{7}$ Kent University, Kent, $\mathrm{OH}$, USA.

Received: 13 July 2018 Accepted: 6 May 2019

Published online: 16 May 2019

\section{References}

1. Schantz-Dunn J, Nour NM. Malaria and pregnancy: a global health perspective. Rev Obstet Gynecol. 2009;2:186-92.

2. Oliveira-Ferreira J, Lacerda MVG, Brasil P, Ladislau JLB, Tauil PL, DanielRibeiro CT. Malaria in Brazil: an overview. Malar J. 2010;9:115.

3. Lapouble O, Santelli A, Muniz-Junqueira M. Situação epidemiológica da malária na região amazônica brasileira, 2003 a 2012. Rev Panam Salud Pública. 2015;38:300-6.

4. Benzecry SG, Alexandre MA, Vítor-Silva S, Salinas JL, De Melo GC, Marinho $\mathrm{HA}$, et al. Micronutrient deficiencies and Plasmodium vivax malaria among children in the Brazilian Amazon. PLoS ONE. 2016;11:e0151019.

5. Fernando SD, Gunawardena DM, Bandara MRSS, De Silva D, Carter R, Mendis KN, et al. The impact of repeated malaria attacks on the school performance of children. Am J Trop Med Hyg. 2003;69:582-8.

6. Fernando SD, Rodrigo C, Rajapakse S. The 'hidden' burden of malaria: cognitive impairment following infection. Malar J. 2010;9:366.

7. Meremikwu MM, Asindi AA, Ezedinachi E. The pattern of neurological sequelae of childhood cerebral malaria among survivors in Calabar, Nigeria. Cent Afr J Med. 1997;43:231-4.

8. Boivin MJ. Effects of early cerebral malaria on cognitive ability in Senegalese children. J Dev Behav Pediatr. 2002;23:353-64.

9. Boivin MJ, Bangirana P, Byarugaba J, Opoka RO, Idro R, Jurek AM, et al. Cognitive impairment after cerebral malaria in children: a prospective study. Pediatrics. 2007;119:e360-6.

10. Holding PA, Snow RW. Impact of Plasmodium falciparum malaria on performance and learning: review of the evidence. Am J Trop Med Hyg. 2001;64:68-75.

11. Carter JA, Mung'ala-Odera V, Neville BG, Murira G, Mturi N, Musumba $C$, et al. Persistent neurocognitive impairments associated with severe falciparum malaria in Kenyan children. J Neurol Neurosurg Psychiatry. 2005;76:476-81. 
12. Vitor-Silva S, Reyes-Lecca RC, Pinheiro TR, Lacerda MV. Malaria is associated with poor school performance in an endemic area of the Brazilian Amazon. Malar J. 2009;8:230.

13. IBGE. Censo demográfico 2010- Caracteristicas da populacao e dos domicilios- Resultados do Universo. Rio Janeiro: Instituto Brasileiro de Geografia e EStatistica; 2011.

14. WHO. Basic malaria microscopy. Pt. 1 Learner's quide. Geneva: World Health Organization; 2010.

15. da Saúde Ministerio. Manual de Diagnóstico Laboratorial da Malária. Brasília: Secretaria de Vigilância em Saúde; 2009.

16. Almeida ACG, Kuehn A, Castro AJM, Vitor-Silva S, Figueiredo EFG, Brasil LW, et al. High proportions of asymptomatic and submicroscopic Plasmodium vivax infections in a peri-urban area of low transmission in the Brazilian Amazon. Parasit Vectors. 2018;11:194.

17. Wechsler D. Wechsler preschool and primary scale of intelligence. San Antonio: Psychological Corp. Harcourt Brace; 1991.

18. Meio MD, Lopes CS, Sichieri R, Morsch DS. Reliability of the WPPSI-R test in the evaluation of cognitive development in preschool children. Cad Saude Publica. 2001;17:99-105 (in Portuguese).

19. Marturano EM, Ferreira Mde C, Bacarji KM. An evaluation scale of family environment for identification of children at risk of school failure. Psychol Rep. 2005;96:307-21.

20. Yang $\mathrm{H}$, de Onis $\mathrm{M}$. Algorithms for converting estimates of child malnutrition based on the NCHS reference into estimates based on the $\mathrm{WHO}$ Child Growth Standards. BMC Pediatr. 2008;8:19.

21. Kvalsvig JD, Cooppan RM, Connolly KJ. The effects of parasite infections on cognitive processes in children. Ann Trop Med Parasitol. 1991;85:551-68.

22. Nokes C, Grantham-McGregor SM, Sawyer AW, Cooper ES, Robinson BA, Bundy DA. Moderate to heavy infections of Trichuris trichiura affect cognitive function in Jamaican school children. Parasitology. 1992;104(Pt 3):539-47.

23. Jardim-Botelho A, Raff S, Rodrigues Rde A, Hoffman HJ, Diemert DJ, Correa-Oliveira R, et al. Hookworm, Ascaris lumbricoides infection and polyparasitism associated with poor cognitive performance in Brazilian schoolchildren. Trop Med Int Health. 2008;13:994-1004.

24. Hoff E. The specificity of environmental influence: socioeconomic status affects early vocabulary development via maternal speech. Child Dev. 2003;74:1368-78.

25. National Institute of Child Health and Human Development Early Child Care Research Network. Duration and developmental timing of poverty and children's cognitive and social development from birth through third grade. Child Dev. 2005;76:795-810.

26. Marques dos Santos L, Neves dos Santos D, Bastos AC, Assis AM, Prado MS, Barreto ML. Determinants of early cognitive development: hierarchical analysis of a longitudinal study. Cad Saude Publica. 2008;24:427-37.

27. Ali NS, Mahmud S, Khan A, Ali BS. Impact of postpartum anxiety and depression on child's mental development from two peri-urban communities of Karachi, Pakistan: a quasi-experimental study. BMC Psychiatry. 2013;13:274.

28. Nelson HD, Nygren P, Walker M, Panoscha R. Screening for speech and language delay in preschool children: systematic evidence review for the US Preventive Services Task Force. Pediatrics. 2006:117:e298-319.
29. Gashu D, Stoecker BJ, Bougma K, Adish A, Haki GD, Marquis GS. Stunting, selenium deficiency and anemia are associated with poor cognitive performance in preschool children from rural Ethiopia. Nutr J. 2016;15:38.

30. Blouin B, Casapia M, Joseph L, Gyorkos TW. A longitudinal cohort study of soil-transmitted helminth infections during the second year of life and associations with reduced long-term cognitive and verbal abilities. PLoS Negl Trop Dis. 2018;12:e0006688.

31. Halpern R, Giugliani ER, Victora CG, Barros FC, Horta BL. Risk factors for suspicion of developmental delays at 12 months of age. J Pediatr (Rio J). 2000;76:421-8 (in Portuguese).

32. Olney DK, Pollitt E, Kariger PK, Khalfan SS, Ali NS, Tielsch JM, et al. Young Zanzibari children with iron deficiency, iron deficiency anemia, stunting, or malaria have lower motor activity scores and spend less time in locomotion. J Nutr. 2007:137:2756-62.

33. Tine RC, Ndiaye M, Hansson HH, Ndour CT, Faye B, Alifrangis M, et al. The association between malaria parasitaemia, erythrocyte polymorphisms, malnutrition and anaemia in children less than 10 years in Senegal: a case control study. BMC Res Notes. 2012;5:565.

34. Serghides L, McDonald CR, Lu Z, Friedel M, Cui C, Ho KT, et al. PPARgamma agonists improve survival and neurocognitive outcomes in experimental cerebral malaria and induce neuroprotective pathways in human malaria. PLoS Pathog. 2014;10:e1003980.

35. Vorasan N, Pan-Ngum W, Jittamala P, Maneeboonyang W, Rukmanee P, Lawpoolsri S. Long-term impact of childhood malaria infection on school performance among school children in a malaria endemic area along the Thai-Myanmar border. Malar J. 2015;14:401.

36. Bangirana P, Opoka RO, Boivin MJ, Idro R, Hodges JS, Romero RA, et al. Severe malarial anemia is associated with long-term neurocognitive impairment. Clin Infect Dis. 2014;59:336-44.

37. Idro R, Kakooza-Mwesige A, Balyejjussa S, Mirembe G, Mugasha C, Tugumisirize J, et al. Severe neurological sequelae and behaviour problems after cerebral malaria in Ugandan children. BMC Res Notes. 2010;3:104.

38. Lampah DA, Yeo TW, Hardianto SO, Tjitra E, Kenangalem E, Sugiarto P, et al. Coma associated with microscopy-diagnosed Plasmodium vivax: a prospective study in Papua, Indonesia. PLoS Negl Trop Dis. 2011;5:e1032.

39. Malta DC, Goulart EMA. Lima e Costa MFF: Nutritional status and socioeconomic factors associated with failure in school: a prospective study of first grade students in Belo Horizonte, Brazil. Cad Saude Publica. 1998;14:157-64 (in Portuguese).

40. Brasil L, Vieira JLF, Araujo EC, Piani PPF, Dias RM, Ventura A, et al. Cognitive performance of children living in endemic areas for Plasmodium vivax. Malar J. 2017:16:370.

41. McLoyd VC. Socioeconomic disadvantage and child development. Am Psychol. 1998;53:185-204.

\section{Publisher's Note}

Springer Nature remains neutral with regard to jurisdictional claims in published maps and institutional affiliations.

Ready to submit your research? Choose BMC and benefit from

- fast, convenient online submission

- thorough peer review by experienced researchers in your field

- rapid publication on acceptance

- support for research data, including large and complex data types

- gold Open Access which fosters wider collaboration and increased citations

- maximum visibility for your research: over 100M website views per year

At $\mathrm{BMC}$, research is always in progress.

Learn more biomedcentral.com/submissions 